Based on paper No. 2519 in Transducers 2015

\title{
An Ocular Iontophoretic Device Using PEDOT Electrode for Local
}

\author{
Drug Delivery \\ Yushi Zhang ${ }^{1}$,Yao Chen ${ }^{2}$, Yangjia $Q i^{l}$, Dong Huang ${ }^{1}, M u$ Yang $^{l}$, Xiaoxue Yu $^{l}$, Yuntao Hu ${ }^{3 *}$, and \\ Zhihong $\mathrm{Li}^{{ }^{*}}$ \\ ${ }^{1}$ National Key Laboratory of Science and Technology on Micro/Nano Fabrication, \\ Institute of Microelectronics, Peking University, Beijing, CHINA \\ ${ }^{2}$ Department of Ophthalmology, Peking University Third Hospital, Beijing, CHINA \\ ${ }^{3}$ Department of Ophthalmology, Beijing Tsinghua Changgung Hospital, Beijing, CHINA
}

\begin{abstract}
An ocular iontophoretic device using a biocompatible planar PEDOT electrode is reported. In vivo experiments on rabbit eyes demonstrated that the device can realize ocular iontophoresis effectively, simply, and conveniently. Compared with conventional eye cups, this device can be placed under the eyelid and deliver ions through a small area on the eyeball, reducing tissue damage during ion penetration. Devices were fabricated in different sizes for different cases. The efficiency was a function of the current, work time and solvent water content. The highest iontophoretic efficiency observed in the in vivo experiments was $396 \mathrm{ng} / \mathrm{mL}$, while the efficiency observed in the controlled experiments was only $2.69 \mathrm{ng} / \mathrm{mL}$. The temperature distribution was simulated and measured, and thermal injuries were not observed under an applied current of $1.5 \mathrm{~mA}$.
\end{abstract}

\section{Keywords: Ocular Iontophoresis, Drug Delivery, PEDOT Electrode}

\section{Introduction}

Iontophoresis is an ion delivery method in which a small electric current is applied to enhance ion penetration into a tissue [1-3]. Over the past few years, it has received increasing attention among researchers as a new non-invasive technique for ionized drug delivery. In particular, ocular iontophoresis has great significance in the treatment and diagnosis of eye diseases. Compared with drug delivery in other parts of the body, however, ocular iontophoresis is faced with more challenges due to the barriers in and fragility of the eyes.

Majority of the reported iontophoretic devices [4-7] had to be pressed onto the eye manually and delivered the drug through a large area on the eyeball. In some cases, the delivered ions could damage the sensitive cornea or sclera. For example, $\mathrm{Mn}^{2+}$, as a tracer to detect eye diseases, could harm the corneas during penetration. Additionally, the electric field in the reservoir was produced by a probe-type electrode, which was less homogeneous than a planar electrode. Recently ocular drug delivery devices and systems based on Micro-Electro-Mechanical Systems (MEMS) technology [8-11] were also investigated, but most of them were invasive and iontophoresis was difficult.

In our previous work, a simple PDMS-based device with a planar PEDOT electrode was proposed and the preliminary results was reported in Ref. [12]. In this paper, the more technical details and latest results, including the simulation of the concentration and the thermal effect analysis, are presented. The device can be placed under the eyelid and deliver the ions through a small area. Devices were fabricated in different sizes for different cases. The electrical characteristics of the device were tested 
and in vivo experiments were conducted on rabbit eyes, which showed that the device can enhance the penetration of the ionized drug into the eyeball. The thermal effects were also analyzed to assess the possible damage that occurred during the iontophoresis process. The simulated temperatures in response to different currents and times coincided with the tested values in in vivo experiments.

\section{Principle and Simulation}

The principle of the device was schematically shown in Fig. 1. As the micro-fabrication technology was utilized, the device based on PDMS in a cup shape with a planar PEDOT electrode can be realized in a small size with the external diameter of $4 \sim 6 \mathrm{~mm}$ and 2 4 $\mathrm{mm}$ inner diameter of the reservoir. The ionized or charged drugs should be dropped to the eye under the eyelid, and can be supplied by more drops added around the device in the eye. The reservoir of the device is also filled with the solution and the device was seated on the sclera of the eye as anode or cathode, while the other electrode is connected on the ear. Applied current in several milliampere, ions or charged molecule in the liquid can be driven into the vitreous cavity by the electric field through iontophoresis, penetrating the corneal epidermis. In our cases, the device is used as the anode while the electrode on the ear is used as the cathode. The positive ions can be driven under $1 \sim 2 \mathrm{~mA}$ with the safe voltage of $2 \mathrm{~V} \sim 5 \mathrm{~V}$. The ion distribution and the temperature during iontophoresis were simulated.

\subsection{Ion Concentration Simulation}

To study the diffusion of the ions in response to an electric field, the concentration distribution was simulated by the COMSOL software, as shown in Fig. 2. In the model, considering the symmetry of the structure, the eyeball was constructed as a 2-D circular shape with a $12 \mathrm{~mm}$ radius in order to simplify the calculation. A $0.2 \mathrm{~mol} / \mathrm{L} \mathrm{Mn}^{2+}$ solution was used as a source of ions with a constant concentration, at the outside surface with $4 \mathrm{~mm}$ in length, referring to the size of the device. The concentration distribution was measured after 300 seconds of free diffusion without an electric field, as shown in Fig. 2(a), and the average concentration of the eyeball was calculated with the result of $5.6 \mathrm{ng} / \mathrm{mL}$. Contrastively, Fig. 2(b) shows the results in response to an applied current of $1 \mathrm{~mA}$ for $300 \mathrm{~s}$ and the average concentration is $194 \mathrm{ng} / \mathrm{mL}$, which indicates that the diffusion distance is obviously increased under the electric field. For further simulated, Fig. 3(c) shows the free diffusion results for $600 \mathrm{~s}$, while Fig. 2(d) shows the results in response to an applied current of $1 \mathrm{~mA}$ for $600 \mathrm{~s}$. The average concentration of the eyeball in the model is $11.2 \mathrm{ng} / \mathrm{mL}$ without an electric field and $389 \mathrm{ng} / \mathrm{mL}$ under $1 \mathrm{~mA}$ current.

Also, the concentrations at $1 \mathrm{~mm}, 2 \mathrm{~mm}$, and $3 \mathrm{~mm}$ diffusion depth varied as a function of time in response to the $1 \mathrm{~mA}$ current and are shown in Fig. 2(f); these concentrations were also far greater than those, in Fig. 2(e). The distribution results of the simulation also indicated that free diffusion time was required for a uniform ion distribution after $600 \mathrm{~s}$ of iontophoresis

\subsection{Thermal Effects Simulation}

The temperature increases due to the heating effect of current, leading to heat injury during iontophoresis. The thermal effects of our device were simulated under various current intensities to analyze the temperature and ensure that the tissue would not suffer heat injury, which can help us design the ranges for the current intensity and time duration in the in vivo experiments.

The contact resistance between the device and eyeball generated heat and increased the local temperature when a current was applied. A device with an inner diameter of $4 \mathrm{~mm}$ and a thickness of 1 $\mathrm{mm}$ was used in the simulation model, and the thickness of the PEDOT electrode layer was $50 \mu \mathrm{m}$. Using a Joule heat model and applying current on a cross-section of the wire, a stationary temperature 
distribution and a general heating process were obtained. Using 1 and $1.5 \mathrm{~mA}$ currents for $600 \mathrm{~s}$, the local highest temperatures around the PEDOT electrode are $36.96{ }^{\circ} \mathrm{C}$ and $39.86{ }^{\circ} \mathrm{C}$, respectively, as shown in Fig. 3(a) and (b). Using a $2 \mathrm{~mA}$ current for $600 \mathrm{~s}$, the temperature is $43.68{ }^{\circ} \mathrm{C}$, as shown in Fig. 3(c). Additionally, the temperature in response to a $2.5 \mathrm{~mA}$ current only for $180 \mathrm{~s}$ is $42.10{ }^{\circ} \mathrm{C} \mathrm{(Fig.} \mathrm{3(d)).}$

\section{Experimental Procedure}

\subsection{Device Fabrication}

PEDOT: PSS solution was prepared as described below. The experiment started with $1 \mathrm{~mL}$ of Clevios PH1000, in which the volumetric ratio of PEDOT (Poly(3,4-ethylenedioxythiophene)) to PSS (Poly(sodium-p-styrenesulfonate)) was 1:1.25. Five vol\% DMSO (dimethylsulfoxide) was added to enhance the conductivity and 0.5 vol\% GOPS ((3-glycidyloxypropyl) trimethoxysilane) added to improve stability. Two mL of IPA was also added to adjust the surface tension and improve the coating properties, without significantly changing the conductivity.

The schematic in Fig. 4 illustrated the simplified device fabrication process. The PDMS wafer was first cut into a circular chip. Approximately $0.5 \mathrm{~mL}$ of the PEDOT:PSS solution was dripped and spread on the PDMS chip, and the chip was heated on a hot plate for $30 \mathrm{~min}$ at $150{ }^{\circ} \mathrm{C}$ to form a dried film on the surface of the chip (Fig. 4(a)). Next, a thin copper wire was fixed on the opposite surface of the chip and connected to the dried PEDOT film by electrargol (Epotek H20E), as shown in Fig. 4(b). Then, a piece of annular PDMS with the same external diameter as the chip was bonded to the PEDOT film by half-polymerized PDMS (Base: Curing=8:1, in mass; heated for $25 \mathrm{~min}$ in $60{ }^{\circ} \mathrm{C}$ ) or medical silica gel, as shown in Fig. 4(c). The bottom and the side face of the device was wrapped with half-polymerized PDMS or medical silica gel for biocompatible isolation (Fig. 4(d)), and the whole device was heated for $60 \mathrm{~min}$ at $60{ }^{\circ} \mathrm{C}$ in an oven.

The devices were fabricated in different sizes for different cases, three of which were shown in Fig. 5(a). In the subsequent in vivo experiments, the device with an inner diameter of $4 \mathrm{~mm}$ and thickness of $1 \mathrm{~mm}$ was tested as an example. The device can be placed under the eyelid of the rabbit during the experiments, as shown in Fig. 5(b) and (c).

\subsection{Testing the Properties of the Device}

To study the electrical characteristics of the devices, they were tested in $0.9 \%$ normal saline using a semiconductor parameter analyzer (HP 4156B). The device using in the following experiments was tested for five times to ensure the stability I-V characteristics. Using Voltammetry, the current intensities were recorded using voltages ranging from $-1 \mathrm{~V}$ to $1 \mathrm{~V}$.

Cyclic voltammetry and the AC impedance method were introduced to analyze the electrochemical properties of the electrode. The electrochemical properties were tested using a CHI 660 electrochemistry work station ( $\mathrm{CH}$ Instruments Co., USA) connected to a computer and a three-electrode system in PBS solution (0.01 M, pH 7.4), where the PEDOT electrode was used as the working electrode, a platinum wire as a counter electrode and an $\mathrm{Ag} / \mathrm{AgCl}$ electrode as the reference electrode. Cyclic voltammetry was performed in the range from $-0.5 \mathrm{~V}$ to $0.5 \mathrm{~V}$ at a scan rate of 0.05 $\mathrm{V} / \mathrm{s}$, and the AC impedance method was performed using frequencies ranging from $10^{2}-10^{5} \mathrm{~Hz}$.

\subsection{In vivo Experiments}

Fig. 5(d) showed the design of the in vivo experiments. Healthy New Zealand white rabbits weighing approximately $2 \mathrm{~kg}$ were used in the experiments. Five minutes before the iontophoresis began, the rabbit received general anesthesia. One hundred fifty $\mu \mathrm{L}$ of $0.2 \mathrm{~mol} / \mathrm{L} \mathrm{MnCl}_{2}$ solution was dropped into the eye of the rabbit, and the reservoir of the device was also filled with the solution. The 
device was seated on the sclera of the right eye as the anode, while the cathode was on the left ear. The hair was removed from the rabbit's left ear and a piece of medical cotton infiltrated with normal saline was seated between the cathode clamp and the bare rabbit ear to reduce the contact resistance. Then, a direct current was applied to the device for iontophoresis. However, current was not applied to the left eye, which served as the control group. To study the individual influences of the current intensity and time a fixed time of $600 \mathrm{~s}$ and $0.5 \mathrm{~mA}, 1 \mathrm{~mA}$ and $1.5 \mathrm{~mA}$ currents were used in one experiment, while a fixed current of $1 \mathrm{~mA}$ and times of $60 \mathrm{~s}, 300 \mathrm{~s}$ and $600 \mathrm{~s}$ were tested in another experiment.

To identify more effective methods, medical hyaluronate gels with $\mathrm{MnCl}_{2}$ were introduced to replace the $\mathrm{MnCl}_{2}$ solution. In this case, the gels only needed to be placed into the device reservoir, but not into the eye, which simplifies the operation. Evy Gel, containing $0.88 \mathrm{~mol} / \mathrm{L} \mathrm{MnCl}$, and Vioscoat Gel containing $0.95 \mathrm{~mol} / \mathrm{L} \mathrm{MnCl}$, were used and iontophoresis was tested for $600 \mathrm{~s}$ using a current of 1 $\mathrm{mA}$.

After iontophoresis and a 30-min incubation to allow the ions to diffuse in the vitreous cavity, the vitreous humor was extracted and Mass Spectrometry was performed to detect the concentration of $\mathrm{Mn}^{2+}$.

\section{Results and Discussion}

\subsection{Device Properties}

As shown in Fig. 6, the I-V curves of the device tested in $0.9 \%$ normal saline show a nonlinear voltage-current relationship and the low DC resistance of the device using a voltage of $1 \mathrm{~V}$. The current was less than $1 \mathrm{~mA}$ when the voltage was under $1 \mathrm{~V}$. The device was tested five times shown as I1 to I5, which show that the device can keep a stable I-V characteristics during the in vivo experiments.

The cyclic voltammetry results for the PEDOT electrode and a comparison with a platinum (Pt) electrode are shown in Fig. 7(a). The charge delivery capacities were calculated, using the formula

$$
\mathrm{Q}_{\mathrm{CDC}}=\frac{1}{v} \int_{E_{C}}^{E_{a}}|i| \mathrm{dE} \quad\left(\mathrm{mC} / \mathrm{cm}^{2}\right),
$$

where $E$ is the electrode potential ( $v s . \mathrm{Ag} / \mathrm{AgCl}$ ), $i$ is the measured current density, $E \mathrm{a}$ and $E \mathrm{c}$ are the anodic and cathodic potential limits, respectively, and $v$ is the corresponding scan rate [14]. It shows that the PEDOT electrode has a higher charge capacity $\left(5.5 \mathrm{mC} / \mathrm{cm}^{2}\right)$ than the Pt electrode $\left(2.1 \mathrm{mC} / \mathrm{cm}^{2}\right)$, and the latter is a widely used bio-electrode.

The electrochemical impedance spectroscopy (EIS) of the PEDOT electrode obtained by the AC impedance method, including the amplitude and the phase, shows that the PEDOT electrode has low impedance and exhibits both capacitive and resistive characteristics using a $1 \mathrm{KHz}$ frequency (Fig .7(b)).

The electrochemical properties of the electrode indicate that the device can still work well for iontophoresis using a double-pulse current (usually with a frequency of $1 \mathrm{KHz}$ ), which means reduced electric current damage compared with the constant current. The PEDOT and PDMS used in the device are both known to be stable, biocompatible materials. Combined with the electrical and electrochemical characteristics, these results suggest that the device can work well in the in vivo experiments. The electrical and electrochemical properties of the device can also be controlled by the thickness of the PEDOT:PSS film for different demands.

\subsection{In vivo Iontophoresis}

The $\mathrm{Mn}^{2+}$ concentrations in response to different currents or times are shown in Table 1 and Fig. 8 (a). It shows that the devices have an obvious effect on ocular iontophoresis. The highest efficiency was $396 \mathrm{ng} / \mathrm{mL}$ using a $1 \mathrm{~mA}$ current for $10 \mathrm{~min}$, while the efficiency in the controlled experiment without iontophoresis was only $2.69 \mathrm{ng} / \mathrm{mL}$. Fig. 8(a) shows that the efficiency for different working time using 
$0.2 \mathrm{~mol} / \mathrm{L} \mathrm{Mn}^{2+}$. Fig. 8 (b) shows that the efficiency decreased as the water content of the solvent was reduced, with the same working time for $600 \mathrm{~s}$. In this case, the ionization proportion decreased, even though the $\mathrm{Mn}^{2+}$ concentration increased, as shown in Table 1. It also showed that the efficiency increased as the working time increased.

The concentration in the simulation was $389 \mathrm{ng} / \mathrm{mL}$ and the highest one in the experiments was $396 \mathrm{ng} / \mathrm{mL}$ when using $1 \mathrm{~mA}$ for $600 \mathrm{~s}$. Also, the concentration in the simulation is $189 \mathrm{ng} / \mathrm{mL}$ and the highest one in the experiments was $154 \mathrm{ng} / \mathrm{mL}$ when using $1 \mathrm{~mA}$ for $300 \mathrm{~s}$. Although there still was a difference between the simulation and the experiments, the efficiency of the device was in the same order of magnitude as the results obtained in the simulation. The little difference between the simulation and the experiments caused by the ideal approximation and the estimation of the simulation model. The eyeball in three-dimensional sphere shape was simplified to a two-dimensional model. Also, the complex structure inside the eyeball, which can affect the movement of the ions, was ignored.

Because of its small size, the MEMS device for ocular iontophoresis can be placed under the eyelid and deliver ions through a small settled portion on the eyeball, reducing tissue damage during ion penetration compared with conventional eye cups. The planar electrode can provide a uniform electric field in the device. Additionally, the PEDOT film can be much thinner, allowing the device to be transparent to easily monitor the condition of the sclera during the iontophoresis.

\subsection{In vivo Thermal Effect Testing}

To study the heat injury during iontophoresis, the temperature during the iontophoresis was assessed using a thermal imager (Fluke TiX640/660). Fig. 9 shows the temperature distribution, including the point with the highest temperature, and current injury under different conditions. Without an applied current, the temperature near the canthus was the highest at $35.7^{\circ} \mathrm{C}$ (Fig. 9(a)). Using 1 and $1.5 \mathrm{~mA}$ currents for $10 \mathrm{~min}$, the highest local temperature was under the device, with temperatures of $36.8^{\circ} \mathrm{C}$ (Fig. 9(b)) and $39.5^{\circ} \mathrm{C}$ (Fig. 9(c)), respectively. The results show that heat injury did not occur with currents less than $1.5 \mathrm{~mA}$ for $600 \mathrm{~s}$.

Two and $2.5 \mathrm{~mA}$ current densities were applied to study the thermal injury. Injury occurred when a 2 mA current was used for $600 \mathrm{~s}$, as shown in Fig. 9(d), in which the highest local temperature was $40.8^{\circ} \mathrm{C}$. Using $2.5 \mathrm{~mA}$ current, thermal injury occurred after only $180 \mathrm{~s}$ (Fig. 9(e)) with $41.6{ }^{\circ} \mathrm{C}$ highest local temperature, which shows that currents more than $2 \mathrm{~mA}$ are not safe.

The highest local temperature was $36.96{ }^{\circ} \mathrm{C}$ under $1 \mathrm{~mA}$ and $39.86{ }^{\circ} \mathrm{C}$ under $1.5 \mathrm{~mA}$ in the simulation, while the highest temperature was $36.8^{\circ} \mathrm{C}$ under $1 \mathrm{~mA}$ and $39.5^{\circ} \mathrm{C}$ under $2 \mathrm{~mA}$ measured during the experiments. Also, using $2 \mathrm{~mA}$ for $600 \mathrm{~s}$, the highest temperature in the simulation and experiments were $43.10{ }^{\circ} \mathrm{C}$ and $41.6{ }^{\circ} \mathrm{C}$ individually. Using $2.5 \mathrm{~mA}$ for $180 \mathrm{~s}$, the highest local temperature in the simulation and experiments were $42.68{ }^{\circ} \mathrm{C}$ and $40.8{ }^{\circ} \mathrm{C}$ individually. Thus the results of the simulation and experiments were nearly coincident. The little difference between the simulation and the experiments caused by the ideal approximation of the simulation model. For example, the thermal transmission between the air and the device was not considered in the simulation but occurred in the experiments. $\mathrm{T}$

\section{Conclusions}

An ocular iontophoretic device using biocompatible planar PEDOT electrodes was fabricated in different sizes for different cases. According to the electrical and electrochemical characteristics, the device can work well, and the in vivo experiments on rabbit eyes indicate that the device can realize ocular iontophoresis effectively, simply and conveniently. The highest iontophoretic efficiency observed 
in the in vivo experiments was $396 \mathrm{ng} / \mathrm{mL}$, while the efficiency in the controlled experiment without iontophoresis was only $2.69 \mathrm{ng} / \mathrm{mL}$. There was no heat injury during iontophoresis with the device using a current of $1.5 \mathrm{~mA}$, as the local temperature was less than $40^{\circ} \mathrm{C}$.

\section{Acknowledgments}

This work was supported by the National Science Foundation of China (No. 91323304) and the National Basic Research Program of China (No. 2011CB707505).

\section{References}

[1] Y. N. Kalia, A. Naik, J. Garrisonc, R. H. Guy, "Iontophoretic drug delivery", Advanced Drug Delivery Reviews 56 (2004), pp.619- 658.

[2] Y. Su, and L. Lin, "A Water-Powered Micro Drug Delivery System", Journal of Microelectromechanical Systems, 13, 1(2004), pp.75-82.

[3] O. Pillai, R. Panchagnula, "Transdermal delivery of insulin from poloxamer gel: ex vivo and in vivo skin permeation studies in rat using iontophoresis and chemical enhancers", Journal of Controlled Release 89 (2003), pp. 127-140.

[4] E. Eljarrat-Binstock, F. Raiskup, J. Frucht-Pery, and Abraham J. Domb, "Transcorneal and transscleral iontophoresis of dexamethasone phosphate using drug loaded hydrogel", Journal of Controlled Release, 106 (2005), pp. 386-390.

[5] J. Frucht-Perya, H. Mechoulama, C. S. Siganosa, P. Ever-Hadanib, M. Shapiroc, and A. Domb, "Iontophoresis-gentamicin delivery into the rabbit cornea, using a hydrogel delivery probe", Experimental Eye Research, 78 (2004), pp. 745-749.

[6] E. Eljarrat-Binstock, and A. J. Domb, "Iontophoresis: A non-invasive ocular drug delivery", Journal of Controlled Release, 110 (2006). pp. $479-489$.

[7] M. Rawas-Qalaji, and C. Williams, "Advances in Ocular Drug Delivery", Current Eye Research, 37, 5 (2012), pp. 345-356.

[8] M. N. Yasin, D. Svirskis, A. Seyfoddin, and I. D. Rupenthal. "Implants for drug delivery to the posterior segment of the eye: A focus on stimuli-responsive and tunable release systems", Journal of Controlled Release, 196 (2014). pp. 208-221.

[9] S. A. Molokhia, H. Sant, C. J. Simonis, J. Bishop, R. M. Burr, B. K. Gale, and B. K. Ambati, "The capsule drug device: Novel approach for drug delivery to the eye", Vision Research, 50 (2010), pp. 680-685.

[10] F. N. Pirmoradi, J. K. Jackson, H. M. Burt, and M. Chiao, "On-demand controlled release of docetaxel from a battery-less MEMS drug delivery device.", Lab Chip, 11(2011). pp. 2744-2752.

[11] P. Li, J. Shih, R. Lo, S. Saati, R. Agrawal, M. S. Humayun, and Y. Tai, E. Meng, "An electrochemical intraocular drug delivery device", Sensors and Actuators A, 143 (2008), pp. $41-48$.

[12] Y. Zhang, Y. Chen, M. Yang, X. Yu, Y. Qi, and Zhihong Li "An ocular iontophoretic device for local drug delivery using PEDOT electrode", the 18th International Conference on Solid-State Sensors, Actuators and Microsystems (Transducers 2015), 21 - 25 June 2015, Anchorage, the USA, pp. 1041-1044.

[13] E. Slavcheva, R. Vitushinsky, W. Mokwa, and U. Schnakenberg, "Sputtered iridium oxide films as charge injection material for functional electrostimulation," Journal of the Electrochemical Society, 151, 7 (2004), pp. 226-237. 


\section{Corresponding Authors}

*Zhihong Li, Peking University, Beijing, 100871, China, Phone: +86-10-62766581; Fax: 86-10-62751789; E-mail: zhhli@ pku.edu.cn

*Yuntao Hu, Department of Ophthalmology, Beijing Tsinghua Changgung Hospital, Beijing, China, E-mail: ythu203@163.com 
a)

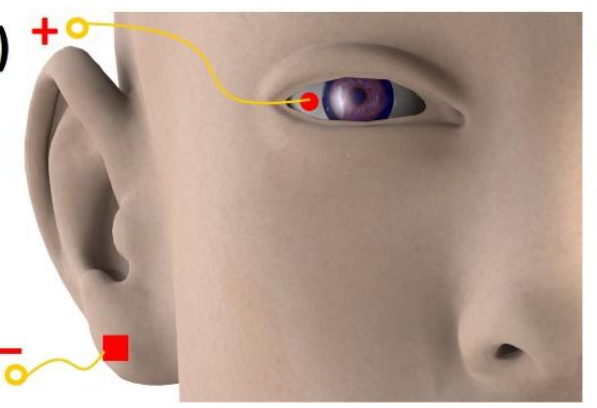

b)

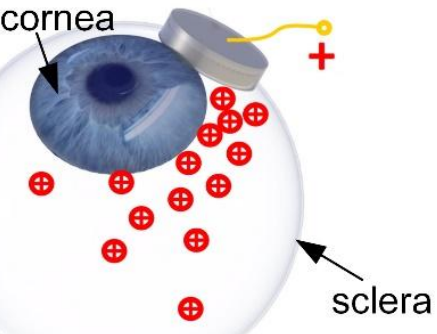

Fig. 1. Schematic view of the ocular iontophoretic device. The device can be placed on a small area of the eyeball and the ions can be driven into the vitreous cavity by an electric field, penetrating the corneal epidermis.

a)

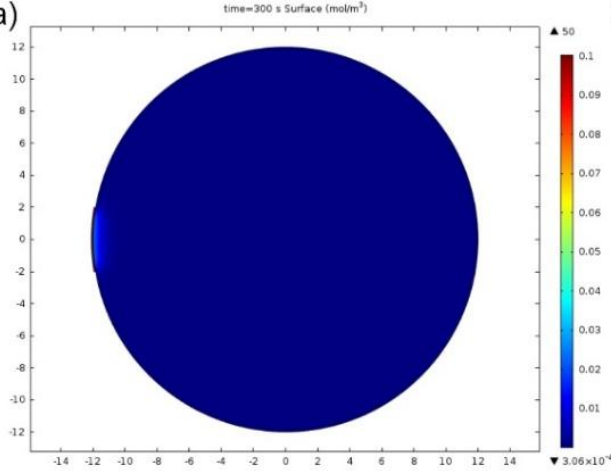

c)

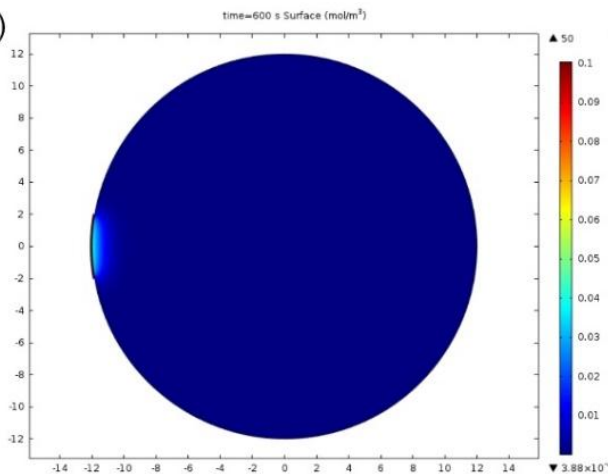

e)

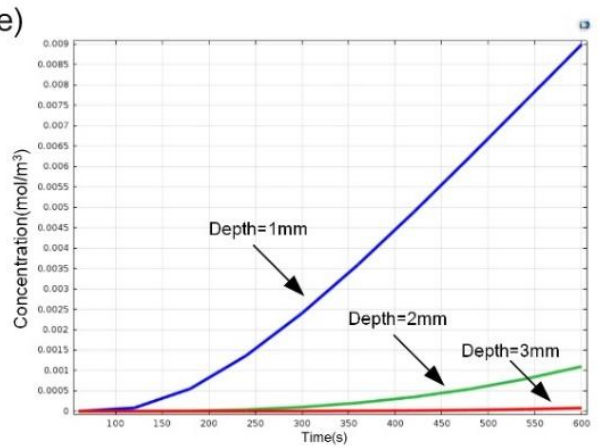

b)

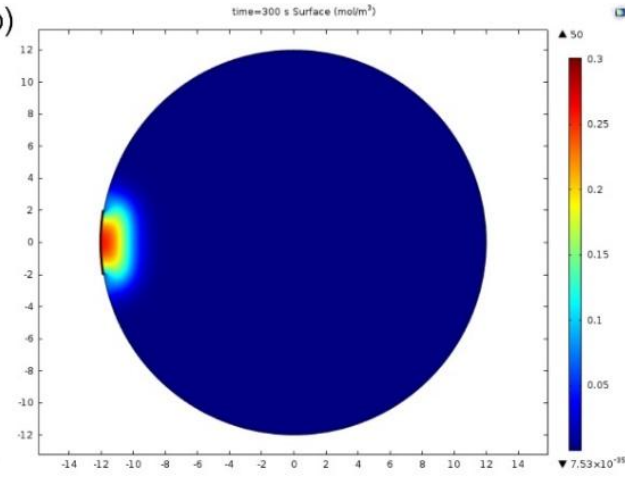

d)

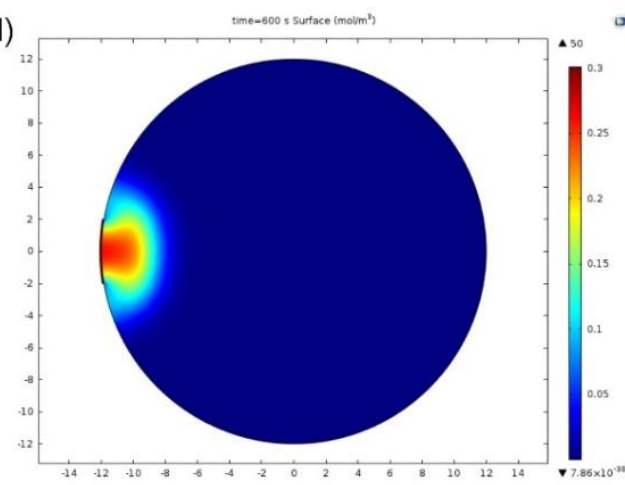

f)

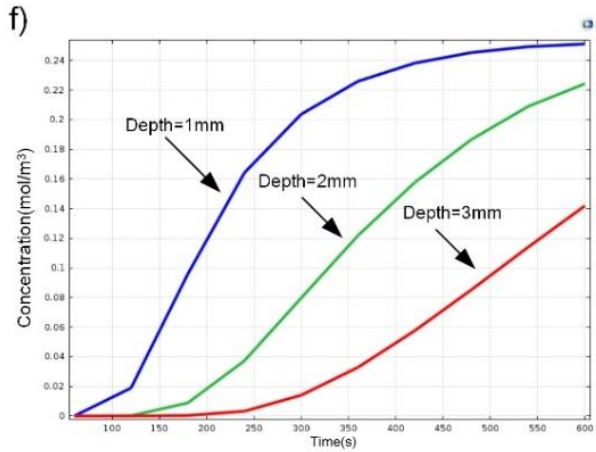

Fig. 2. The concentration simulation of the iontophoresis: (a) concentration distribution for $300 \mathrm{~s}$ using free diffusion without current applied, (b) concentration distribution for $300 \mathrm{~s}$ using $1 \mathrm{~mA}$ current, (c) concentration distribution for $600 \mathrm{~s}$ using free diffusion without current applied, (d) concentration distribution for $600 \mathrm{~s}$ using $1 \mathrm{~mA}$ current, (e) varying concentrations as a function of time using free diffusion without voltage, and (f) varying concentrations varied as a function of time using $1 \mathrm{~mA}$ current. 


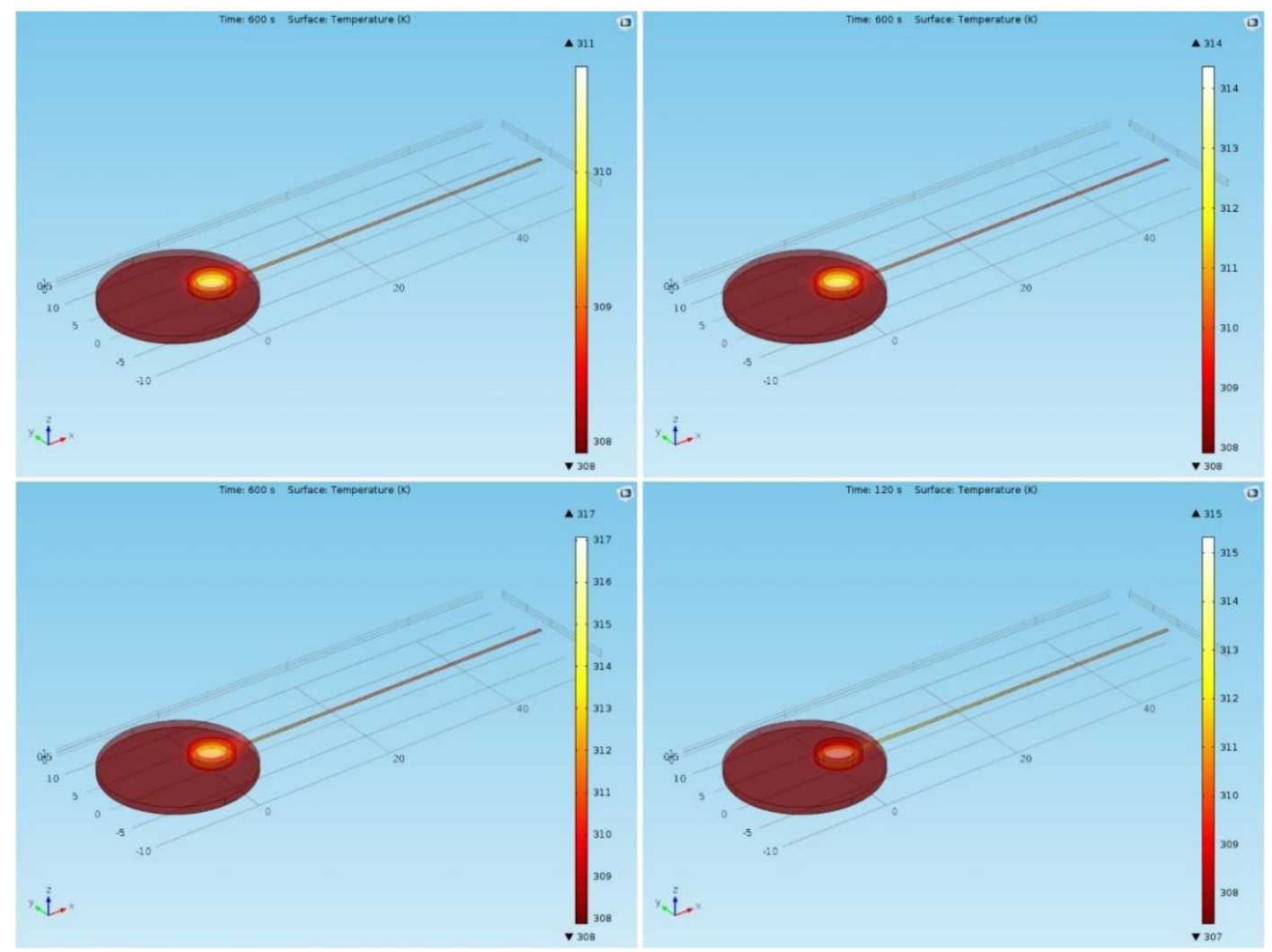

Fig. 3. Thermal effect simulation results: (a) $\mathrm{I}=1 \mathrm{~mA}, \mathrm{t}=600 \mathrm{~s}$ and $\mathrm{T}=36.96{ }^{\circ} \mathrm{C}$; (b) $\mathrm{I}=1.5 \mathrm{~mA}, \mathrm{t}=600 \mathrm{~s}$ and $\mathrm{T}=$ $39.86{ }^{\circ} \mathrm{C}$; (c) $\mathrm{I}=2 \mathrm{~mA}, \mathrm{t}=600 \mathrm{~s}$, and $\mathrm{T}=43.68^{\circ} \mathrm{C}$; (d) $\mathrm{I}=2.5 \mathrm{~mA}, \mathrm{t}=180 \mathrm{~s}$, and $\mathrm{T}=42.10^{\circ} \mathrm{C}$.

a)

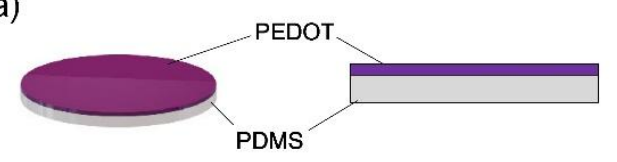

c)

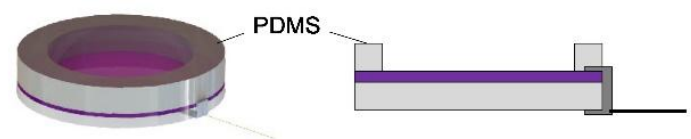

b)

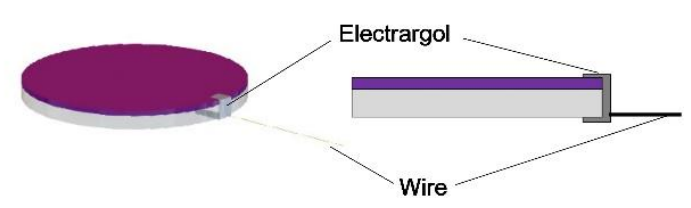

d)

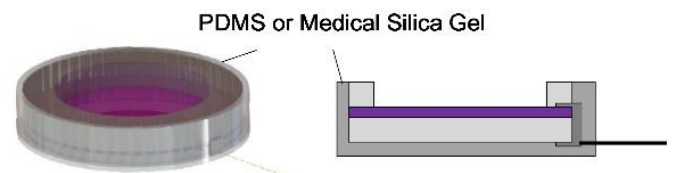

Fig. 4. The schematic of the fabrication process includes the 3D sketch (left) and sectional view (right) in each figure: a) constructing the PEDOT film on a piece of PDMS; b) connecting a wire to the dried PEDOT film by electrargol; c) bonding with a piece of annular PDMS; and d) wrapping the bottom and the side face of the device with half-polymerized PDMS or medical silica gel for insulation. 

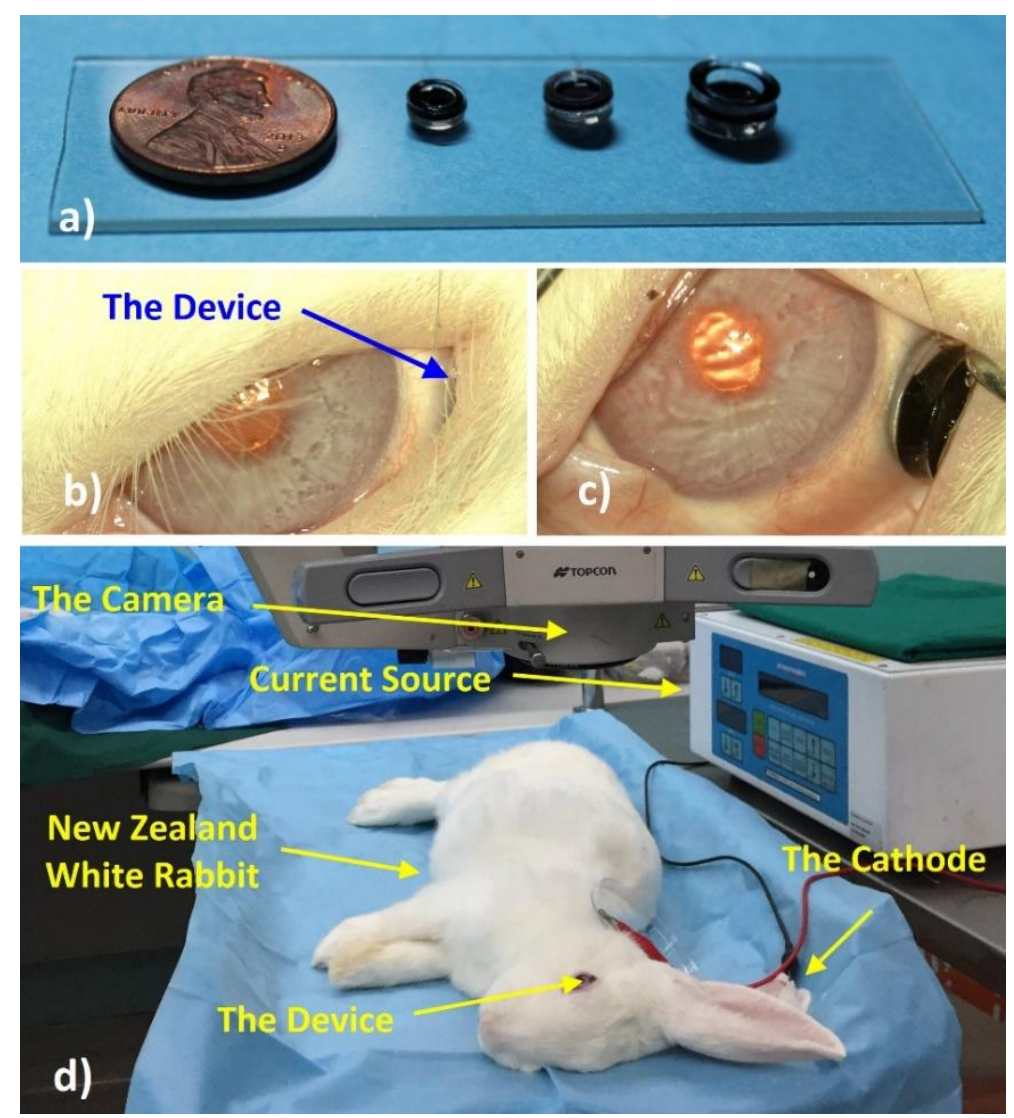

Fig. 5. Photos of the experiments: a) the fabricated devices in different sizes; b) and c) the device under the eyelid; d) the experimental setup.

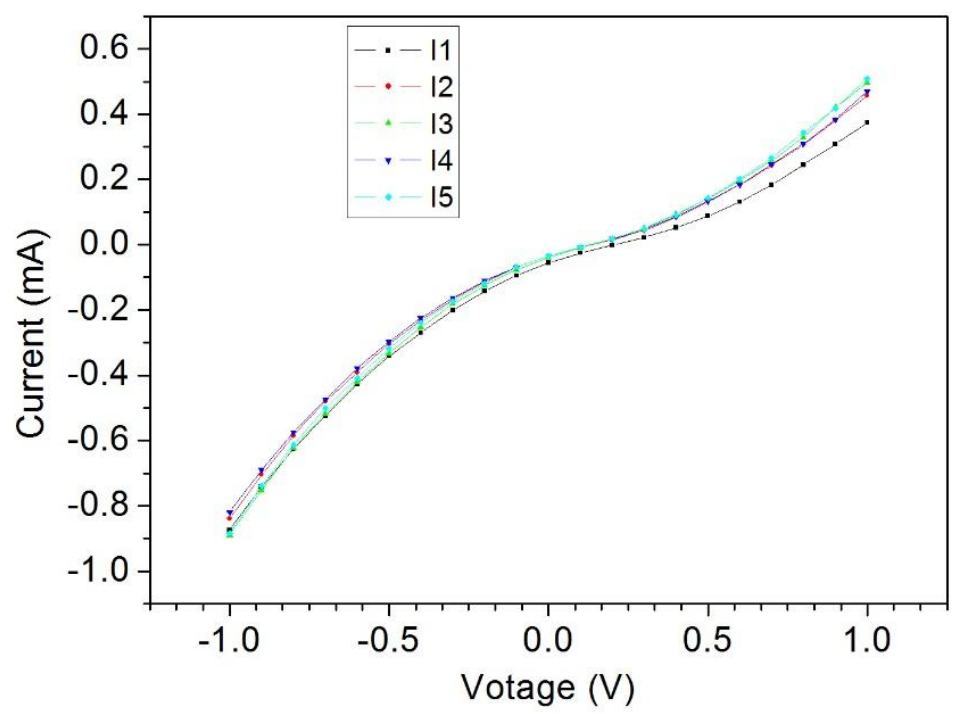

Fig. 6. Electrical characteristics testing results: the voltage current curves of the device was tested in normal saline for five times, shown as I1 to I5. 

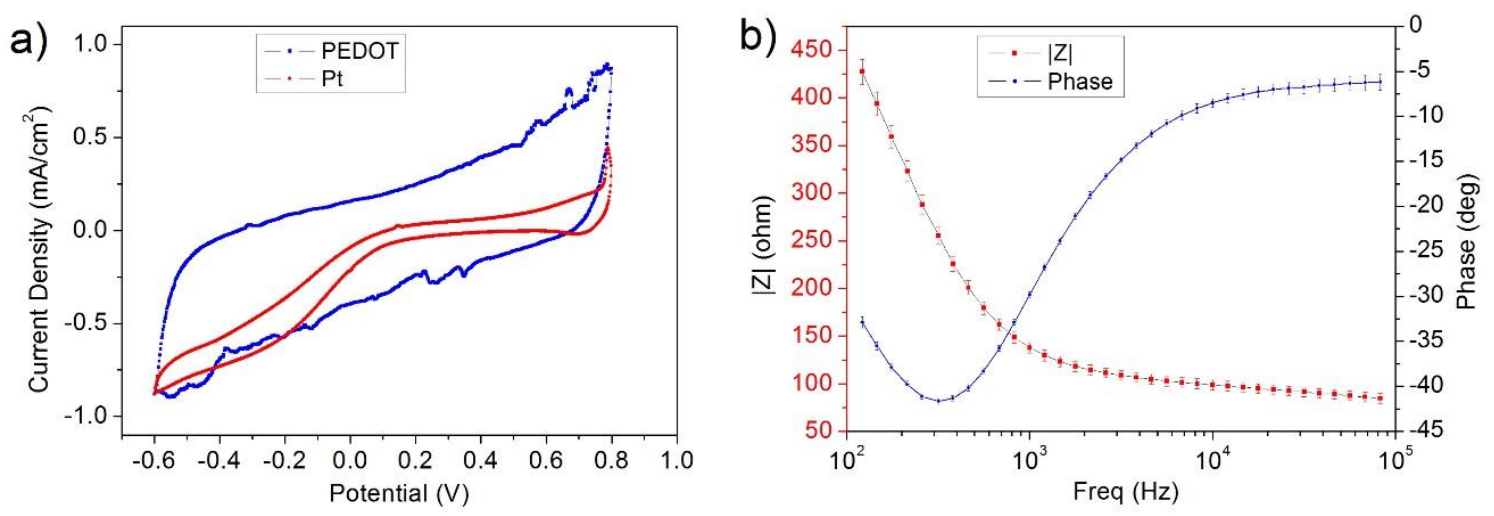

Fig. 7. The electrochemical properties of the device. a) The cyclic voltammetry testing result and b) the impedance of the device.
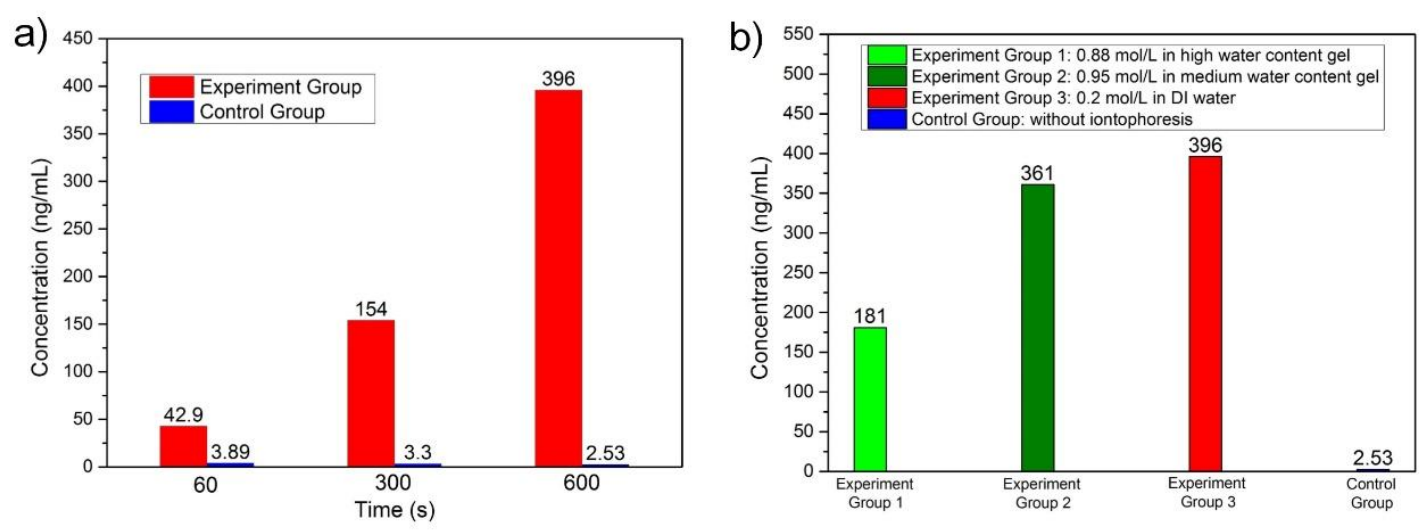

Fig. 8. Iontophoresis efficiency (a) for different working time using $0.2 \mathrm{~mol} / \mathrm{L} \mathrm{Mn}^{2+}$ in DI water, and (b) in different solvents for $600 \mathrm{~s}$. 

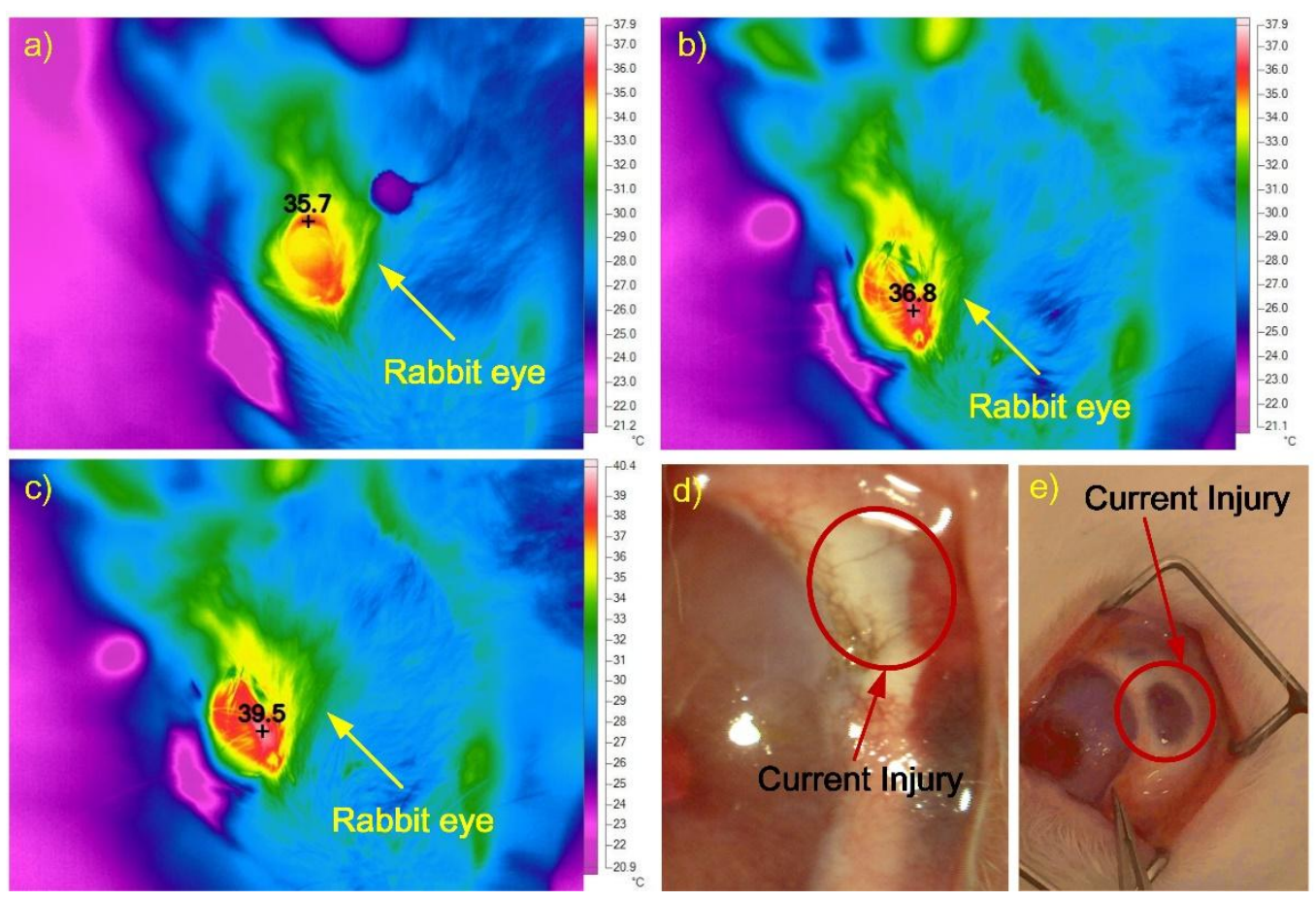

Fig. 9. Thermal effect during the iontophoresis: a) the temperature distribution without current; $b$ ) the temperature distribution using $1 \mathrm{~mA}$ for $600 \mathrm{~s}$; c) the temperature distribution using $1.5 \mathrm{~mA}$ for $600 \mathrm{~s}$; ) the current injury using $2 \mathrm{~mA}$ for $600 \mathrm{~s}$; and e) the current injury using $2.5 \mathrm{~mA}$ for $180 \mathrm{~s}$. 
Table 1 The $\mathrm{Mn}^{2+}$ concentration in the vitreous cavity in different conditions

\begin{tabular}{|l|c|c|c|c|c|c|}
\hline Number & $\begin{array}{c}\text { Current } \\
(\mathbf{m A})\end{array}$ & $\begin{array}{c}\text { Time } \\
(\mathbf{s})\end{array}$ & $\begin{array}{c}\mathbf{M n}^{2+} \text { in the } \\
\text { experiment } \\
\text { eye } \\
(\mathbf{n g} / \mathbf{m L})\end{array}$ & $\begin{array}{c}\mathbf{M n}^{2+} \text { in the } \\
\text { controlled } \\
\text { eye } \\
(\mathbf{n g} / \mathbf{m L})\end{array}$ & $\begin{array}{c}\text { Drug solvent and } \\
\text { concentration }\end{array}$ & Comments \\
\hline Rabbit 1 & 0.5 & 600 & 169.40 & 2.14 & $0.2 \mathrm{~mol} / \mathrm{L}$ in DI water & \\
\hline Rabbit 2 & 1.0 & 600 & 396.32 & 2.69 & $0.2 \mathrm{~mol} / \mathrm{L}$ in DI water & \\
\hline Rabbit 3 & 1.0 & 600 & 361.89 & 1.7 & $0.88 \mathrm{~mol} / \mathrm{L}$ in Evy Gel & higher water content gel \\
\hline Rabbit 4 & 1.0 & 600 & 181.7 & 3.31 & $0.95 \mathrm{~mol} / \mathrm{L}$ in Vioscoat gel & medium water content gel \\
\hline Rabbit 5 & 1.5 & 600 & 48.18 & 1.69 & $0.2 \mathrm{~mol} / \mathrm{L}$ in DI water & \\
\hline Rabbit 6 & 2.5 & 180 & 109.61 & 2.5 & $0.2 \mathrm{~mol} / \mathrm{L}$ in DI water & Sclera damage \\
\hline
\end{tabular}

